\title{
10
}

\section{ELITE INTERVIEWING}

\section{The effects of power in interactions. The experiences of a northern woman}

\section{Lotta Lounasmeri}

- Are you a social scientist?

- I believe I am.

- And a $\mathrm{PhD}$ ?

- Yes.

- And you don't know this law?

Who is the interviewer here or, rather, the interrogator?

Throughout my research career, the subject of power has intrigued me: the exercise of power in social settings, whether in written media texts, speeches, images or public and private interactions. As a female academic and a professional in my own field, I wanted to investigate and explain how power works in our societies, but I found myself in the midst of situations defined by those very power relations: here I was, doing a research interview and getting myself utterly questioned and undermined. Finding myself in a defensive position, being left feeling inferior and most of all - fearful and shamed. Wondering why this was, and finding that I, as a woman, had certain experiences of being in this professional world and relating to male interviewees. In my most recent project on political decision making on energy issues, the subject of power hierarchies and my emotions it brought to the surface became the most obvious. I started having discussions about this with my Norwegian colleague who had done extensive interview research in the Nordic countries. It became clear I was not alone in my experiences; it seemed that these encounters with holders of power in society were challenging to start with, but there was an additional aspect to us being women. These discussions led to an exercise in critical reflexivity with a feminist touch, which I address in this chapter: a critical examination of the negotiation of power relations from a gender perspective. 


\section{Introduction}

In this chapter, I wish to shed light on the question of how power differences are expressed in interviews between academics and societal elites and how gender plays a role in these situations. This approach requires that I step into unknown territory, viewing my own experiences and emotions as legitimate parts of the research conducted. The traditional social science approach of political science and media and communication studies does not favour or emphasise reflecting on personal experiences. Even though this stress on objectivity demands that we maintain our distance and a degree of abstraction and steer away from the personal, the genre of science - not only anthropology or related disciplines - clearly could benefit from being expanded towards emotional understanding and intuition. Anthropologists such as George Devereux (1967) and Sandra Harding (1987) believed that if researchers acknowledge their subjectivity, they and their work would gain greater objectivity. Researchers' conclusions are necessarily influenced by their personal beliefs, values and behaviour, so it is imperative to assess them as part of the evidence in research.

Mainstream social scientists representing the fields of political science and media studies typically proceed from a general level or a systemic framework and apply its presumed laws to specific local environments and individual cases. In contrast, the anthropological approach starts with the specific, the local and the here and now. In the best case, the anthropological approach can combine a more general political and economic framework with a detailed cultural analysis. The starting point of anthropology is empirical field experience. The general thinking holds that for research to be valid and reliable, other researchers should be able to replicate it in identical conditions and get the same results. But in the human sciences this is an awkward premise. As Ruth Behar (1996) has observed, anthropologists' conversations and interactions in the field can never be reproduced exactly because like all encounters between people, they are unique. Proof of anthropologists' journey of exploration comes in the form of an ethnography whose value lies in what others can learn from a meaningful, identifiable account. As the old story of a group of blind people feeling an elephant tells us, their descriptions of the animal they have never come across will differ from each other, but all versions are equally true and accurate.

Emotions have been a subject of interest to philosophers and anthropologists for centuries, and a discussion on the relevance of emotions to politics has already persisted for decades (Ahmed 2014, 2-19). As Sara Ahmed (2014, 9) has stated, many researchers have argued that emotions should not be seen as merely psychological states but also as social and cultural practices. Such claims have several implications. My emotion is not only mine, but something collective, that is born out of the community. It has a history; it comes to the surface in this very moment but is linked to past collective experiences. I might spend much time contemplating what it is that actually evokes the emotions that I felt during the interviews, that I interpret as connected to fear: shame, guilt, frustration, vulnerability, 
humiliation and anxiety, as well as anger. In the end, this question is difficult to answer, and it might suffice to understand that these feelings stem from the oppression experienced by women by men - intensified by their powerful positions - a history that exists in the collective, also in the Nordic countries.

Examining the powerful in society is not an easy task, but it is important if we are to understand how they affect how any community takes shape and follows a certain path. Recent decades have seen increased interest in elite interviewing and growth in the literature on the dilemmas of interviewing elites within the social sciences (Djerf-Pierre 2005). This literature identifies common barriers to information and gives researchers practical advice on how to circumvent or lower these barriers (Figenschou 2010, 964). At the heart of elite interviewing, as my personal example shows, are questions of power and power imbalances. The negotiation of status and power is relevant to all research relationships, and to enhance the quality of research interviews, an open, systematic approach to these challenges is necessary (Figenschou 2010, 974).

The body of data on which I draw was collected in three research projects conducted in 2011, 2013-2014 and 2017-2018. For these projects, I interviewed retired Finnish chief editors and media executives (all male), public relations and public affairs consultants (mostly male) and decision makers in the energy sector (mostly male but also female). The last group included senior officials in the political and civil administrative sectors as well as energy companies. Most interviews took place in the interviewees' offices, but as most participants in the first group were retired, the interviews were conducted in their homes or public places. As a researcher, I was on culturally familiar ground in terms of nationality. Moreover, Finland, one of the Nordic countries, is characterised by high gender equality and low hierarchies, allowing easier access to those in powerful positions. However, different kinds of power hierarchies still come into play in our interview interactions: hierarchies between different fields of society, between societal positions and, as I came to experience, between genders.

\section{Theoretical background to a story of challenging encounters}

Amid the current revival of the debate on elites' positions and relationships with other segments of societies, reflections on the role of elites in knowledge production and research are both necessary and relevant. To give a definition, I see elites as ruling groups who hold strategic and central positions in society that enable them to regularly influence significant societal decisions (Dogan and Higley 1998; Etzioni-Halevy 1993). Elites possess considerable power due to their positions in social, political and economic networks, and they have the potential to exercise this power to control and define interview situations. One must also acknowledge the layers of elites; some occupy top positions, and others belong to so-called sub-elite groups, to borrow Eva Etzioni-Halevy's (1993) term. With the recognition that membership in elite groups is not equally distributed among men and women, one important aspect of this discussion becomes the large gender differences within and 
between elite groups (Hjellbrekke and Korsnes 2016), which have implications for the power relations in interview situations (Odendahl and Shaw 2001). I take this point as my feminist lens through which I try to interpret my personal experiences as an interviewer. In describing my elite encounters, I wish to reveal something subtle but deep: What happens when a female researcher in a softer field of science meets with the hardcore male engineer or high-up politician? How can this encountering help to understand how power plays out in their everyday work?

I discuss this issue from a feminist, intersectionalist position which permits choosing various methods according to the discipline involved (Reinharz 1992, 240-243). As Reinharz has explained, feminism strives to represent human diversity and initiate social change, including in the researcher as a person. Feminism can enhance the understanding of one's own participation in socially constructed realities, both personally and politically. I also draw on insights from indigenous methodologies and writings that have highlighted the embodiment of the research process and question the ontologies of scientific practices (Kovach 2009; Smith 2012).

Interviewing, as a research method, constitutes an interaction between the researcher and the informant. By itself, interviewing is not necessarily defined as an ethnographic method; it is a qualitative method used across the social and human sciences and in medicine, psychology and other disciplines. However, interviewing top decision-makers poses a special challenge for ethnography as the power relationship between the interviewer and the interviewee is the reverse of that in interviews with ordinary people. Knowledge is created in the constructive process between the interviewer and the interviewee, and power is always an aspect of the process. Social scientists face well-known challenges when doing research that uses elite interviews as a data gathering method (Figenschou 2010; Kvale and Brinkmann 2009). Nevertheless, textbooks on interviewing methods regularly state that the power imbalance between the interviewer and the interviewee demands ethical awareness in the researcher, who frequently has the power to define the situation. Social anthropology faces similar questions related to power and the power imbalance between the researcher and the subjects of research, which are contrary to my context: the researcher appears superior to those on whom she wishes to turn her inquisitive gaze, as, for instance, in Behar's (1996) comments on her early work on Spanish peasants.

When the interviewees are members of society's elites, however, the imbalance of power likely favours them, which raises particular questions concerning interview interactions and knowledge production. When aspiring to understand and somehow engage with the powerful in society, the researcher either is easily refused access or meets with a penetrating gaze from the research subjects. Typically, elite informants carefully protect their interests and may attempt to manipulate interviews. The power imbalance can also be observed in limited time availability, questions of anonymity and secrecy and less obvious factors such as unwillingness to shed light on the material the researcher seeks and behaving in patronising and aggressive ways in interviews. 
In essence, I see power as a relationship and a contingent condition arising in every moment. Taking a Foucauldian approach, structures and positions offer individuals possibilities to exercise power, but it is visible in the action they take how they use that potential. Power always comes to life in social practices. Individuals also possess different kinds of potential power. Here, one can also refer to Pierre Bourdieu's (1998) idea of fields and Robert Putnam's (2000) notion of social capital. Conti and O'Neil $(2007,68)$ argued that power is not an intrinsic property of individuals but, rather, flows from the complex relationships among individuals, organisations and institutions. Manuel Castells (2009) discussed the variants of network power and networked power. Paying close attention to the dynamics of power can help us see more clearly what the potential limits and possibilities of power are - for both parties of an interaction.

Drawing on feminist methodological approaches, Conti and O'Neill $(2007,67)$ have stated that "the power dynamic between the researcher and elite informant[s] not only shapes the interview process but defines how knowledge is created". Feminist researchers have introduced the idea of the micropolitics of research, meaning that the researcher should carefully reflect on all stages of the research process to understand their roles and those of the informants in the production of new knowledge. The researcher should do as thorough and transparent an examination as possible, and this reflection can be seen as a central point in the documentation and dissemination of research (Bhavnani 1991; 1994).

Practicing critical but compassionate reflexivity helps the researcher understand herself and others. In the case of these interview studies dealing with societal power, the interview situations and the research process both evoked a whole host of emotions in me as the researcher. It is hard to remain cool and detached when the research purpose is to uncover powerful people's motives, ideals and values when they are dealing with important societal matters. In fact, in this case, doing so would have been impossible: the interviews initially filled me with a sense of dread and fear so intense that there was absolutely no point in trying to project the role of a disinterested, professional researcher, at least in my own eyes. I came to realise how important it is that the researcher engages with the emotional material that arises during involvement and interactions with the research subjects. Devereux (1967) captured this point, stating that what happens with the observer must be made known to understand the nature of what is being observed. The observer and the object of observation both influence the outcome.

\section{Negotiating the power balance}

Describing my own experience of what happened in the interviews involves explaining how I draw from these encounters. In introducing my data, I draw on the transcribed interview texts, the field notes I wrote about the interviews and my recollections of the specific situations I describe. Going back in time to those situations certainly presents a challenge, but when faced with intense emotional experiences, the body and the mind remember. This account, of course, is 
subjective and changing as time passes. In analysing the interviews, I paid special attention to the contextual elements such as pauses, interruptions and the interviewees' comments related to the interview setting itself. Moreover, I address what the interviewees disclosed about the research subject itself and how they did so whether they explicitly drew lines on what they would disclose or stuck to the official story, among other actions.

The tangible background characteristics of the interviewee and the interviewer are important dimensions of the interview dynamics (Kahn and Cannell 1957). These characteristics include elements such as cultural and ethnic backgrounds, age, gender, education and institutional and professional positions. These elements constitute the subjectivities and social locations of both parties. At the same time, one must acknowledge that the resources of power can differ and change, as can the balance of power between the interviewer and the interviewee. More intangible elements such as charisma and psychological and physical conditions have relevance. The researcher's task is to try to understand and reflect on these elements as thoroughly as possible (Haraway 1988; Bhavnani 1994; Conti and O’Neil 2007, 66).

At the time of these interviews, I was in my late thirties and early forties and a Finnish postdoctoral researcher conducting externally funded projects. Having a $\mathrm{PhD}$ was a prerequisite to conduct meaningful interviews, and interestingly, my funding source was also a relevant factor. Securing interviews was most difficult for the energy policy project, but my funding from the Academy of Finland gave me credibility and persuaded especially the public actors who, at least in theory, had a different responsibility towards scientific research.

Interviewing people of the same cultural and ethnic background is easy in a way as both parties have tacit and shared knowledge on a range of subjects and use their mother tongue to discuss issues. A downside is the risk of taking things for granted. Accordingly, as a Finnish person, I found it rather uncomplicated to approach the interviews with other Finns as social situations. The aspects that played more significant roles, instead, were differences in institutional and professional positions in society, along with age and gender.

Academia constitutes a field of power in its own right, and the informants might see the potential influence of research. In Finland, despite the public debate on the position and relevance of universities, elites in society still hold academia in high respect, this being the old tradition. Tine Figenschou $(2010,974)$ noted that in her research, she could be perceived as having power to influence the public image of her research subjects. Similarly, I have experienced that looking into critical, strategic and taboo subjects aroused the informants' interest in varied ways. They either wished to avoid scrutiny, if possible, or to have their say and defend their case to influence how the issue was interpreted. Still others wished to act as whistle blowers, revealing certain grievances or abuses in society (usually after they had already exited certain circles of power). That said, most of the interviewees still strove to exert firm control over the interactions. 
Another matter is the professional fields represented by the interviewers and the interviewees. Social scientists and humanities researchers might find it especially challenging to find a common language when the interviewees have different competences such as technical, engineering and natural sciences backgrounds. This following excerpt gives an example of the situations I encountered when the interviewees and I had markedly different fields of expertise:

- You are a social scientist right?

- Yes, I am, and a media researcher. That is one term to use.

- So do you have any idea of how many different subjects there are in the Finnish legal system where an administrative decision has to be taken to the parliament?

- No, this is not the kind of thing I research.

- Okay you don't have an idea, but it doesn't matter, as the answer is easy, there is only one, and it is that decision-in-principle. How well do you know the history of these matters [nuclear decision making]?

- I know [them] to a certain degree, yes.

- You know what happened in the beginning of the nineties? [Starts explaining ...]

- What really interests me is your own point of view, if you could tell me, to start with, about your own career and how you have come to this ...

In many interviews with the male respondents who were experts in different fields, I had to answer questions about my knowledge of the subject in question and make efforts to steer the interviews towards the issues in which I was interested. This situation aroused a certain amount of frustration of which I was conscious during the interviews, and I had to concentrate on keeping my focus and staying calm. This issue did not come up with the female interviewees, even those who were engineers. Instead, they sometimes expressed interested in hearing about my field of expertise:

- I understand the nature of this research, and, is it correct that you are writing an article-based [book], or is it a ...?

This issue was less significant when conducting interviews with media professionals. Issues related to the role of journalism in society came up with the older-generation chief editors, while issues of the role of political communication arose with the consultants. However, I saw these as substantial questions about values and, as such, interesting research results. The consultants were mostly male, and many were close to my age or even younger. We shared similar expertise, so they showed much more understanding and appreciation of my work. The political consultants' field was new in Finland, so it was important for them to appear legitimate and "look good". 
In some situations, the interviewees sought for confirmation if they had understood my questions right:

- Was this what you asked about? [After a long answer]

- Yes, it was. So can you think of why it is that people don't trust each other anymore? If it was different before.

- I don't know if this is the right answer, but I would somehow think that it is because ...

Interview dynamics involve mutual interactions: showing appreciation can result in receiving it. In many cases, the balance of power is unequal, but it can also lead the interviewees to see the researcher as not an equal and perhaps not worthy of respect, time and information. Researchers studying elites have described how the interviewees' sense of authority often shape the interviews (Fitz and Halpin 1994; Hirsch 1995; Odendahl and Shaw 2001). How does this authority manifest in interviews? In what ways can the interviewee try to control the situation? It is often challenging for the interviewer to stay conscious of when and how this happens. The power imbalance does not necessarily become an obstacle if the interviewee is willing to share and disclose information, but more challenges arise if the interviewee strongly attempts to conceal issues and divert, manipulate and belittle the interviewer.

In my experience, the interviewees either were not willing to share or were cautiously trying to figure out how much to share. The research topics in question might have been difficult and ones the interviewees did not easily discuss; the topics also often involved confidential and strategically important information. The topics might have related to embarrassing details, and the interviewees might have been concerned for their reputation, other consequences, or simply for losing face. In a rather collegial experience, a consultant interviewee was willing to share an embarrassing story but wanted to make sure it would not leak:

- I could tell one example, but I don't want it to become very public - of a social media blunder ...

- This is completely confidential. I will not cite you by name anywhere.

- Otherwise you can, but this example that I will tell, I don't want it to get out.

One might also interpret this interviewee as a person who knew exactly what to and what not to disclose. In another example, a consultant wished to make sure that not even his occupation would be shared:

- It's kind of like... I will speak more directly with you when I know this [his background] will not come out. Because then, if the rules are different, I will, of course, regulate my speech accordingly.... If someone can identify me, then that will have an effect [on how I speak]. 
In the interviews, I experienced efforts to control the situation that were either overt and obvious or quite subtle and polite. In some cases, the informants wanted to open up, most probably for their own reasons and interests. The ways in which the informants chose to interact in these situations derived from not only their professional positions but also their individual personalities. These subtler nuances might have become more visible in the familiar cultural context. My interviewees used subtle gestures and openings such as body language (closing up or taking a very assertive pose), inserting delays and obstacles into initial contacts, establishing how much time was available, demanding confidentiality and asking questions about the research and the researcher. Some tactics clearly were targeted at confirming what I knew, asking about what I knew, hinting that maybe I did not, and trying to find out my motivations and personal opinions. I was also often interrupted to provide answers while the questions were still being posed. Sometimes the interviewees attempted to define what was relevant to the research:

- How would you place [your paper]? If we think of the time when you started in the 1970s, what kind of a paper was it in the Finnish newspaper world?

- -well I don't know if that bears much relevance here, what is relevant concerning your research is that I was chosen [for this position] to change the paper's stance towards the Soviet Union...

- How would you define this concept of self-censorship?

- Well, there is no one definition that exists -

- Correct, there is not, but how do you understand it?

Establishing trust was consistently, if not always, easier with the female interviewees, perhaps because a certain kind of sisterly bonding occurred, if only on a professional level. The women would always bond as equals, with very few exceptions when they refused to do the interviews altogether. The female interviewees might have behaved strategically, but they did not try to question my professionalism and capabilities as the interviewer.

With the male interviewees, the interaction and the balance of trust was negotiated differently. In fact, the male interviewees had more difficulty relating on only a professional level. They unconsciously adopted various roles: the older interviewees sometimes acted as father figures, younger ones would come out as charmers, and some would take a role as educators. In certain cases, the latter role was performed in oppressive and aggressive manners, as discussed. However, the quality of the interactions did not affect the research process in straightforward ways. The male interviewees might have talked more and end up telling more willingly or unwillingly - than their female counterparts. Moreover, the male interviewees' reactions demonstrated which questions raised the most emotions. For me as a researcher on societal power, the interview situations themselves yielded much material on the subject.

In the most difficult experiences, the interviewees, invariably male, acted defensively. Showing myself as a person rather than merely a cool professional 
might have led some interviewees to resort to aggressive, fear-driven behaviour. Such behaviour left me feeling intimidated and even fearful. I tried to stay calm and observe the interviewees while acknowledging that I had to use all my concentration to be able to ask the next relevant question. In one interview, I witnessed a consultant bossing around his employees as if to demonstrate his superiority. In another case, a chief editor demanded a detailed account of the interview but did not understand that he would only receive a transcribed text I would later use to analyse the discussion. I, as a researcher, naturally would not subject the analysis to interference from the interviewee. To be fair, once the research was completed, the interviewee did admit that qualitative research was an unfamiliar field to him.

\section{Reflections and conclusions}

I see that in my experiences, the issue of gender became intertwined with my societal and professional positions, and these latter characteristics carried much more weight for the male than the female interviewees. Had I been older and a professor, I might have encountered less questioning. Odendahl and Shaw (2001, 311) have emphasised that gender is an issue in many interview situations, and female interviewers of elite subjects invariably appear more aware of the positive and negative influences their gender may have on the interview process. I was certainly aware, and must admit to the weirdest thing I have expressed in an academic text: maybe my overtly feminine physical appearance played a part here, too. Personal characteristics are important too, and feeling not so confident from the start certainly bore relevance. The less I knew the field I was looking into, the less certainty I felt. Perhaps fear is contagious - catching on from either side of the table?

A particular dilemma arises when the interviewer needs to distinguish when the informants are using an official discourse or institutional language and when they are lying. When a story has a strong, official version and a significantly different, unofficial version, the informants must invest much energy into putting up a show or a façade to convince the interviewer. These efforts can be detected as nervousness, arrogance and the behaviour of closing up and refusing to say much. The interviewees might be uncertain of their position, might feel afraid for some reason or might have a need to show their power and position. Uncertainty might be caused by fears of admitting to making mistakes, not knowing or understanding everything and not trusting the interviewer to be benevolent or take the interviewees' side in matters. The interviewees might be afraid that their motives will be misinterpreted or, worse, their motives that cannot stand the light of day will become apparent. Such situations arose with some of my male interviewees, possibly because I attempted to make personal contact with them.

When experiencing power imbalances and their various consequences in interview situations, how should researchers respond and act? Several researchers have problematized or confessed to practicing types of manipulation themselves (Conti 
and O'Neil 2007; Figenschou 2010). Conti and O'Neil (2007, 79) feel that the authority relationship in the interview must be strategically managed. Earlier research, though, has found little need to protect elites from the researcher's power in the practice of studying elites (Cookson 1994, 129; Hertz and Imber 1995). For example, Beth L. Leech $(2002,665)$ has recommended that the researcher pretend to be agreeable and intellectually dim to avoid the risk of causing the respondents to feel threatened. Figenschou (2010, 973) observed that by ignoring patronising behaviour, she may have encouraged her informants' perceptions that she was naive and inexperienced, leading them to open up more. Catherine Welch et al. (2002, 625) suggested that the researcher encourage the informants' openness by steering a course between the roles of therapist and spy, stressing academic neutrality while showing empathy towards the interviewees.

My own experience tells me that confronting informants who behave patronisingly might not be a good strategy. In any case, the fear I felt on many occasions led me to feel vulnerable, and not especially prone to assertiveness, so I chose to maintain neutral and restrained. I believe that the researcher, as an ethical actor, should attempt to establish mutual respect. Instead of confrontation, it is better to maintain one's own dignity and give space for others' behaviour, so it can also become visible to them. The researcher can aim to create mutual trust by displaying her competence, work ethic and personality through being open, acting professionally and trying to connect on a human level. This comes back to vulnerability - showing one's authentic self. Showing myself meant that I did not try to overtly challenge my respondents but let them speak, and I gently steered the topic towards my interests. This approach might have resulted in obtaining more information, but in some cases, it might have had the opposite effect: the informants did not think I was worth sharing information with as they could not know whether I understood it or whether I was "worth it". Some interviews left me feeling humiliated and wondering how difficult it was to connect across that power gap. These feelings occasionally led me to question my professionalism and competence. Ultimately, my position allowed me to not take the actions of the powerful for granted. Maybe my role became one of a spying therapist.

It takes courage for the researcher to actually put herself on the line and to be a person, not just a representative of academia. Giving full, even heartfelt attention to the interviewees always makes a difference. Everyone needs to be heard, and the interviewer can provide that space where others can talk as much as they want. Often, if not always, this space making makes it possible to rise above liturgical speech and overt control and manipulation of situations. The interviewees also often want to talk about their work and what is important to them.

From my part, in the end, there was no other option but to surrender: to be vulnerable, to take the risk that the interviewees would think that I was stupid or disingenuous and wonder what the purpose of the interview was. However, as Behar (1996) wrote, communicating in vulnerable ways creates a good chance that others will also do so and abandon their cool professionalism. Perhaps most importantly, this has the potential to transform self and others, making them more conscious and 
thereby more willing to make efforts to build bridges between the familiar and the strange or unknown - the self and others (see Chang 2008, 52). Authentic communication can also entail healing wounds and liberating oneself to become selfempowered (Foster, McAllister and O'Brien 2005). Through these interactions, both parties share something and there is an opportunity to be affected in some way moved, touched, changed even? Provided that fear does not take over.

\section{Acknowledgements}

I wish to present my heartfelt thanks to my colleague, professor Eli Skogerbo, for her invaluable support in writing this article.

\section{References}

Ahmed, S. 2014 [2004]. The Cultural Politics of Emotion. 2nd edn. Edinburgh: Edinburgh University Press.

Behar, R. 1996. The Vulnerable Observer. Boston: Beacon Press.

Bhavnani, K-K. 1991. Talking Politics: A Psychological Framing for Views from Youth in Britain. Cambridge: Cambridge University Press.

Bhavnani, K-K. 1994. "Tracing the contours: Feminist research and feminist objectivity". In The Dynamics of "Race" and Gender: Some Feminist Interventions, edited by H. Afshar and M. Maynard, 26-40. London: Taylor \& Francis.

Bourdieu, P. 1998. Practical Reason. On the Theory of Action. California: Stanford University Press.

Castells, M. 2009. Communication Power. Oxford: Oxford University Press.

Chang, H. 2008. Autoethnography as Method. California: Left Coast Press.

Conti, J. A., and M. O’Neil. 2007. "Studying power: Qualitative methods and the global elite". Qualitative Research 7 (1): 63-82.

Cookson, P. 1994. "The Power Discourse: Elite Narratives and Educational Policy Formation". In Researching the Powerful in Education, edited by G. Walford, 116-130. London: UCL Press.

Devereux, G. 1967. From Anxiety to Method in the Behavioral Sciences. New York: Humanities Press.

Djerf-Pierre, M. 2005. "Lonely at the top: Gendered media elites in Sweden". Journalism 6 (3): 265-290.

Dogan M, and J. Higley. 1998. "Elites, crises, and regimes in comparative analysis". In Elites, Crises and the Origins of Regimes, edited by M. Dogan and J. Higley. Oxford: Rowman \& Littlefield.

Etzioni-Halevy, E. 1993. The Elite Connection. Problems and Potential of Western Democracy. Cambridge: Polity Press.

Figenschou, T. 2010. "Young, female, Western researcher vs. senior, male, Al Jazeera officials: Critical reflections on accessing and interviewing media elites in authoritarian societies". Media, Culture \& Society 32 (6): 961-978. https://doi.org/10.1177/0163443710379667

Fitz, J., and D. Halpin. 1994. "Ministers and mandarins: Educational research in elite settings". In Researching the Powerful in Education, edited by G. Walford, 32-50. London: UCL Press.

Foster, K., M. McAllister and L. O’Brien. 2005. "Coming to autoethnography: A mental health nurse's experience". International Journal of Qualitative Methods 4 (4): 1-15. 
Haraway, D. J. 1988. "Situated knowledges: The science question in feminism and the privilege of partial perspective". In Feminism and Science, edited by E. F. Keller and H. E. Longino, 249-263. Oxford: Oxford University Press.

Harding, S. G. 1987. Feminism and Methodology. Social Science Issues. Bloomington: Indiana University Press.

Hertz, R., and J. B. Imber. 1995. Studying Elites Using Qualitative Methods. Thousand Oaks: Sage.

Hirsch, P. M. 1995. “Tales from the field: Learning from researchers' accounts". In Studying Elites Using Qualitative Methods, edited by R. Hertz and J. B. Imber, 72-80. Thousand Oaks: Sage.

Hjellbrekke, J., and K. Olav. 2016. "Women in the field of power". Sociologica (2): 1-28.

Kahn, R. L., and C. F. Cannell. 1957. The Dynamics of Interviewing. New York: John Wiley $\&$ Sons.

Kovach, M. 2009. Indigenous Methodologies: Characteristics, Conversations, and Contexts. Toronto: University of Toronto Press.

Kvale, S., and S. Brinkmann. 2009. Interviews. Learning the Craft of Qualitative Research Interviewing. 2nd edn. Los Angeles: Sage.

Leech, B. L. 2002. "Asking questions: Techniques for semistructured interviews". PS: Political Science \& Politics 35 (4): 665-668.

Odendahl, T., and A. M. Shaw 2001. "Interviewing elites". In Handbook of Interview Research: Context and Method, edited by J. F. Gudbrium and J. A. Holstein, 299-316. Thousand Oaks: Sage.

Putnam, R. D. 2000. "Bowling alone: America's declining social capital". In Culture and Politics, edited by L. Crothers and C. Lockhart, 223-234. New York: Palgrave Macmillan.

Reinharz, S. 1992. Feminist Methods in Social Research. New York: Oxford University Press.

Smith, L. T. 2012. Decolonizing Methodologies: Research and Indigenous Peoples. London: Zed Book. Kindle.

Star, S. L. 1979. "Strategic heresy as scientific method: Feminism and the psychology of consciousness". Paper presented at the American Association for Advancement of Science.

Welch, C., R. Marschan-Piekkari, H. Penttinen, and M. Tahvanainen, M. 2002. "Corporate elites as informants in qualitative international business research". International Business Review 11 (5): 611-662. 